\title{
Fotocatálise heterogênea para remoção de azul brilhante FCF: cinética via redes neurais sob baixa incidência solar
}

A indústria têxtil é uma das que mais geram efluentes que poluem corpos hídricos. Corantes azoicos são difíceis de serem degradados naturalmente do ambiente e são bastante encontrados em águas residuais. Esses contaminantes são na grande maioria tóxicos, mutagênicos e carcinogênicos. Os mesmos afetam a qualidade da água e impactam do desenvolvimento da fauna e da flora que compõe esse ecossistema. Por essa razão, surge a necessidade de tratar os efluentes têxteis antes de serem lançados no corpo receptor. Dentre diversas técnicas de tratamento de efluentes a fotocatálise heterogênea é eficaz na remoção de poluentes orgânicos. Neste trabalho, foi avaliada a degradação do corante têxtil azul brilhante FCF por meio de fotocatálise heterogênea utilizando como catalisador o ZnO. Foram utilizadas como fontes de radiação a luz solar em condições climáticas de baixa luminosidade e luz de lâmpada UVC potência $60 W$. Fo proposto o uso de um reator operando em batelada com sistema supervisório de controle onde foi coletado as amostras de forma automática. Como parâmetros da degradação, foram proposto o uso de um reator operando em batelada com sistema supervisório de controle onde foi coletado as amostras de forma automática. Como parâmetros da degradação, foram se mostrou adequado ao processo, tanto sob radiação UVC como em radiação solar, apresentando um coeficiente de correlação superior a 0,967 para o conjunto de experimentos realizados. A aplicação do estudo fotocatalítico em cidades mais frias e com menor teor de radiação por conta das condições climáticas ambientais, proporcionou um bom resultado para o ajuste cinético aplicado ao corante azul brilhante FCF. Dessa forma, a baixa radiação UV não é uma limitação para a aplicação de tratamentos desse componente químico via reações fotocatalíticas visando a remoção de contaminantes orgânicos.

\section{Heterogeneous photocatalysis for removal of bright blue FCF: kinetics via neural networks under low solar incidence}

\begin{abstract}
The textile industry is one of the industries that generates the most effluents that pollute water bodies. Azocolourants are difficult to be naturally degraded from the environment and are widely found in wastewater. These contaminants are mostly toxic, mutagenic and carcinogenic. They affect water quality and impact the development of the fauna and flora that make up this ecosystem. For this reason, the need arises to treat textile effluents before they are released into the receiving body. Among several effluent treatment techniques, heterogeneous photocatalysis is effective in removing organic pollutants. In this research, the degradation of the textile dye bright blue FCF was evaluated by heterogeneous photocatalysis using ZnO as catalyst. Sunlight was used as radiation sources in low light climatic conditions and UVC lamp light $60 \mathrm{~W}$ power. It was proposed the use of a reactor operating in batch with supervisory control system where the samples were collected automatically. As degradation parameters, the catalyst dosage and the type of radiation applied were evaluated by factor planning. A kinetic control system where the samples were collected automatically. As degradation parameters, the catalyst dosage and the type of radiation applied were evaluated by factor planning. A kinetic
model using artificial neural networks was also developed where it was adequate to the process, both under UVC and solar radiation, presenting a correlation coefficient higher than 0.967 for the set of experiments performed. The application of the photocatalytic study in a colder city with lower UV radiation content, compared with other Brazilian cities that have more intense UV index, provided good results of kinetic adjustment, as already mentioned, and consequently effective removal of the dye bright blue FCF. Thus can be explored the potential of these cities in the degradation of organic contaminants via photocatalytic reactions. The application of the photocatalytic study in colder cities with lower radiation content due to environmental climate conditions, provided a good result for the kinetic adjustment applied to the dye bright blue FCF. Thus, the low UV radiation is not a limitation for the application of treatments of this chemical component via photocatalytic reactions to remove organic contaminants.
\end{abstract}

Keywords: Photocatalysis; Dye bright blue FCF; Photocatalytic reactor; Neural networks; Kinetics.

Reviewed anonymously in the process of blind peer.

Érica Janaina de Moraes Dantas (iD) Universidade Federal de Pernambuco, Brasil http://lattes.cnpq.br/2969951711119223 http://orcid.org/0000-0002-0464-0342 ericaaadantas@gmail.com

Isabelle Cristine Prohmann Tschoeke (iD Universidade Federal Rural de Pernambuco, Brasil http://lattes.cnpq.br/1308106432646901 http://orcid.org/0000-0002-0958-4386 isabelletschoeke@gmail.com

Josivan Pedro da Silva Universidade Federal de Pernambuco, Brasil http://lattes.cnpq.br/1251191721735872 http://orcid.org/0000-0003-3294-9352 josivan silva@hotmail.com

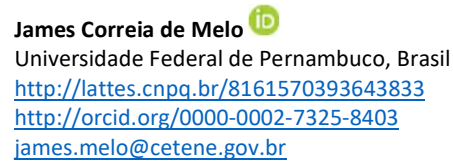

Romero Luiz Mendonça Sales Filho (it)

Universidade Federal Rural de Pernambuco, Brasil http://lattes.cnpq.br/4252707165390630 http://orcid.org/0000-0001-6491-9161 romero.filho@ufape.edu.br

Werônica Meira de Souza

Universidade Federal Rural de Pernambuco, Brasil http://lattes.cnpq.br/9039652038717693 http://orcid.org/0000-0002-6270-2345 weronica.meira@ufape.edu.br
Marilene da Silva Lima (10)

Universidade Federal Rural de Pernambuco, Brasil http://lattes.cnpq.br/8373599117775134 http://orcid.org/0000-0001-8003-8962 marilene.lima@ufape.edu.br

Thibério Pinho Costa Souza (D) Universidade Federal de Pernambuco, Brasil http://lattes.cnpq.br/4506927856419053 http://orcid.org/0000-0001-9452-948X thiberio.souza@ufape.edu.br
6

DOI: 10.6008/CBPC2179-6858.2021.002.0035
Referencing this:

DANTAS, E. J. M.; TSCHOEKE, I. C. P.; SILVA, J. P.; MELO, J. C.; SALES FILHO, R. L. M.; SOUZA, W. M.; LIMA, M. S.; SOUZA, T. P. C. Fotocatálise heterogênea para remoção de azul brilhante FCF: cinética via redes neurais sob baixa incidência solar. Revista Ibero Americana de Ciências Ambientais, v.12, n.2, p.410-418, 2021. DOI: http://doi.org/10.6008/CBPC2179-6858.2021.002.0035 


\section{INTRODUÇÃO}

A energia elétrica é fundamental para o desenvolvimento dos países e para a qualidade de vida das pessoas. O crescimento da população mundial, associado ao desenvolvimento tecnológico e industrial, conduz a um grande aumento da demanda energética, ou seja, quanto mais os países se desenvolvem, mais se torna necessário aumentar a produção de energia. Este aumento na demanda energética é utilizado para o tratamento de efluentes industriais como os obtidos na indústria têxtil. Devido a isso, é de fundamental importância fazer uso de fontes alternativas de energia para tratar efluentes, pois muitas das fontes de energia utilizadas atualmente têm volumes limitados e poderão se esgotar em um horizonte de algumas décadas (KNIJNIK, 1994).

O uso da radiação solar como fonte de energia para a degradação de efluentes da indústria têxtil é uma alternativa que vem sendo utilizada a muitos anos. No Brasil, o índice de radiação solar é um dos mais altos do mundo. Grande parte do território brasileiro está localizada relativamente próxima a linha do Equador, de forma que não se observam grandes variações de radiação solar durante o dia.

Dentre as empresas que mais consomem energia e água nos seus processos produtivos destaca-se o setor têxtil. O uso expressivo de corantes sintéticos principalmente pelas indústrias têxteis ocasiona em uma crítica contaminação ambiental. Aproximadamente $20 \%$ da água doce disponível está contaminada por corantes (GUPTA et al., 2015). Corantes quando despejados em mananciais aumentam a demanda bioquímica e química de oxigênio, prejudicam a fotossíntese, inibem o desenvolvimento das plantas, podem ser biocamulados no organismo além de ser tóxico, mutagênico e carcinogênico (LELLIS et al., 2019). Os processos oxidativos avançados (POA) são um conjunto de técnicas capazes de gerar radicais altamente oxidantes que são capazes de reagir com contaminantes orgânicos e inorgânicos, aumentando a biodegradabilidade de águas residuais (DENG et al., 2015).

Dentre diversos tipos de POAs, a fotocatálise heterogênea faz uso de um material semicondutor que quando exposto a uma fonte de radiação UV, produz radicais hidroxilas 'in situ' que degradam a estrutura molecular dos contaminantes presentes na água residual. A fotocatálise heterogênea permite a mineralização de componentes tóxicos e quando essa remoção não é completa, há geralmente formação de componentes menos tóxicos e mais fáceis de serem degradados que os contaminantes iniciais (CUERDACORREA et al., 2019; ASGHAR et al., 2015). A fotocatálise heterogênea é eficaz na remoção de corantes têxteis tanto em soluções sintéticas como em efluentes (COPETE-PERTUZ et al., 2018; MELO et al., 2018; MISTURA et al., 2019).

A degradação de um corante está sujeita a uma série de reações químicas complexas e simultâneas. Devido a isso, é interessante que se utilize ferramentas de cálculo capaz de auxiliar no estudo deste processo. Métodos robustos de modelagem podem ser aplicados para representar matematicamente este complexo processo, como é o exemplo do uso de redes neurais artificiais (RNAs). Uma rede neural pode receber múltiplos dados de entrada como o tempo, as intensidades de radiação solar e UV, quantidade de catalisador, entre outros. Dessa forma, as redes neurais podem gerar uma curva de concentração da degradação do Azul 
brilhante FCF ao longo do tempo. Uma RNA é capaz de correlacionar múltiplas entradas à diversas saídas aplicadas na análise de cinéticas de degradação (BARBOSA et al., 2019; NASCIMENTO JUNIOR et al., 2017; AQUINO et al., 2019; ROCHA et al., 2017; SANTANA et al., 2019). Neste contexto, as RNAs permitem gerar modelos que tem se mostrado eficientes em descrever reações de degradação.

Neste trabalho foi realizado uma modelagem cinética via redes neurais artificiais, capaz de descrever matematicamente a degradação do corante azul brilhante FCF por meio de fotocatálise em diferentes fontes de radiação (UVC e solar natural). Diversos fatores experimentais foram analisados para se obter os parâmetros cinéticos, tais como nível de catalisador, e tipo de fonte de energia. Foi estudado também a influência do clima do ambiente na fotodegradação, pois os experimentos foram realizados no inverno da cidade de Garanhuns, localizada no agreste pernambucano com temperatura média anual de apenas $20,4^{\circ} \mathrm{C}$.

\section{METODOLOGIA}

A primeira etapa da pesquisa consistiu na montagem do reator fotoquímico solar. Foram utilizados uma célula de reação com capacidade para 2 litros, válvula automática de coleta, unidade controladora e lâmpada UV E27 60W. Também foi montado um sistema de medição de níveis UV (Ultravioleta) com capacidade de se obter o potencial energético em $\mathrm{W} / \mathrm{m}^{2}$. Foi utilizado um sensor de luz Ultravioleta Gy-8511 Ml8511 UV. Em seguida foi instalado no reator fotoquímico para a medição de níveis de absorção dos raios UV. Para auxiliar o controle e monitoramento do processo, foi montado um supervisório de controle para obtenção dos dados funcionando 24 horas por dia. $O$ esquema de montagem do reator pode ser visto na Figura 1.

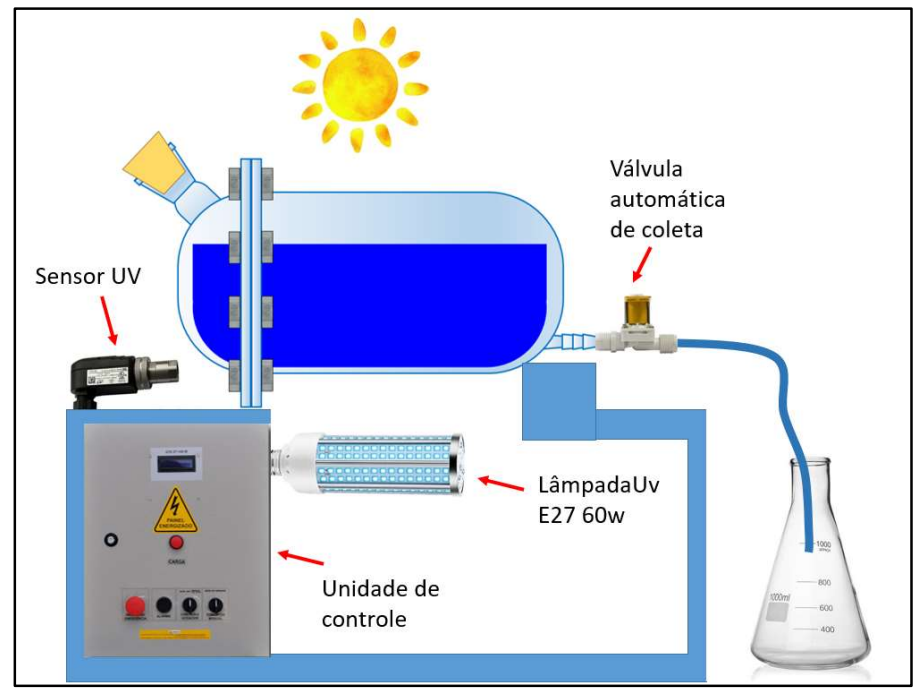

Figura 1: Reator fotoquímico proposto para remoção de corante têxtil.

Os experimentos em ambientes externos foram realizados em situações climáticas de baixa luminosidade com a medição da intensidade de radiação solar sendo feita pela leitura dos sensores. Foi realizado um experimento a nível comparativo de resultados com o reator operando com luz UVC. Para isto, o reator ficou confinado em uma sala escura iluminado apenas por uma lâmpada UV E27 60W pelo mesmo período de tempo respeitando as mesmas condições de processo. 
Foram preparadas soluções aquosas do corante azul brilhante FCF $\left(\mathrm{C}_{37} \mathrm{H}_{34} \mathrm{~N}_{2} \mathrm{Na}_{2} \mathrm{O}_{9} \mathrm{~S}_{3}, 792.85 \mathrm{~g} \mathrm{~mol}^{-1}\right)$ obtido da Dinâmica Química Contemporânea Ltda., e os fotocatalisadores ZnO (área superficial de $5 \mathrm{~m}^{2} . \mathrm{g}$ ) fornecido pela Biodinâmica Química e Farmacêutica Ltda.

A fotodegradação ocorreu por meio de radiação solar natural. Antes da realização do experimento de degradação, foi realizado uma medição da intensidade solar no período de duas semanas. Os dados foram monitorados 24 horas por dia pelo sistema supervisório registrando assim a intensidade de radiação média solar. Os experimentos conduzidos sob radiação solar natural foram realizados na cidade de Garanhuns-PE em dias encobertos, no período de duas semanas seguidas 24 horas por dia.

A intensidade de radiação média foi medida por um sensor de radiação solar (luz Ultravioleta Gy8511 Ml8511 UV). Já para os experimentos com o reator em operação seguiram o planejamento a fim de se obter a curva cinética ajustada por redes neurais artificiais (RNA).

As amostras foram coletadas ao longo do tempo durante o experimento. Após a coleta das amostras, o catalisador foi separado por uma etapa de centrifugação a fim de minimizar a influência nas leituras. Posteriormente, as absorbâncias das amostras foram medidas em um espectrofotômetro UV/Visível. Os picos de absorbância foram medidos no comprimento de onda $650 \mathrm{~nm}$. A concentração inicial das amostras foi de $20 \mathrm{ppm}$. Os experimentos seguiram o planejamento fatorial apresentado na Tabela 1.

Tabela 1: Planejamento fatorial $2^{2}$

\begin{tabular}{lll}
\hline Variável & Nível (-1) & Nível (+1) \\
\hline Catalisador $(\mathrm{g} / \mathrm{l})$ & 0,2 & 0,35 \\
Tipo de radiação & UVC & Solar \\
\hline
\end{tabular}

Para o desenvolvimento da modelagem por redes neurais, um software foi desenvolvido em linguagem C\# utilizando o Unity ${ }^{\odot}$. Chamado de Neural Educator, foi possível gerar um conjunto de procedimentos que tornaram este ajuste rápido e intuitivo. 0 tipo de rede utilizada foi do tipo 4:4:1. Sendo 4 entradas (intensidades de radiação UVC, intensidades de radiação solar, quantidade de ZnO utilizada e tempo), 4 neurônios na camada oculta e 1 neurônio de saída o que gera a concentração nas condições dadas, o método de treinamento se baseia em um conjunto de técnicas aplicadas em conjunto (BERGSTRA et al., 2012), onde uma pequena perturbação é feita nos parâmetros da rede (pesos e vieses) para verificar se a rede resultante se adequa melhor aos dados experimentais.

O tempo de treinamento foi de 30 minutos em um computador de mesa convencional. Os critérios de qualidade do ajuste foram o erro absoluto médio e o coeficiente de determinação $R^{2}$. Foi utilizada uma rede neural feedforward, com função de ativação sigmoide entre -1 e 1 exposta pela Equação 1 a seguir.

$$
\phi(\mathrm{x})=\frac{2}{1+e^{-x}}-1
$$

Para realizar a entrada de dados na RNA, os valores foram normalizados e estabelecidos entre -1 e 1 $<-[0,100]$. Os dados de saída que também foram normalizados entre -1 e $1<-[0.025,1]$ para todo o conjunto de dado, a fim de evitar a saturação dos neurônios e dos parâmetros, conforme exposto por Haikin (1999). 


\section{RESULTADOS E DISCUSSÃO}

Verificou-se que a temperatura máxima para o funcionamento do reator fotoquímico solar durante o período do experimento foi em torno de $25^{\circ} \mathrm{C}$ uma vez que a cidade de Garanhuns-PE apresenta clima frio durante boa parte do ano. Mesmo com o céu bastante encoberto, os valores obtidos pela leitura dos sensores indicaram uma condição mínima de aproveitamento energético da luz solar para a aplicação do reator fotoquímico. Isso é um fator relevante visto que os valores de índices de UV acima deste, contribuirão para um maior potencial energético, favorecendo ainda mais a implantação dos reatores fotoquímicos. A Figura 2 mostra o registro do clima no período estudado.

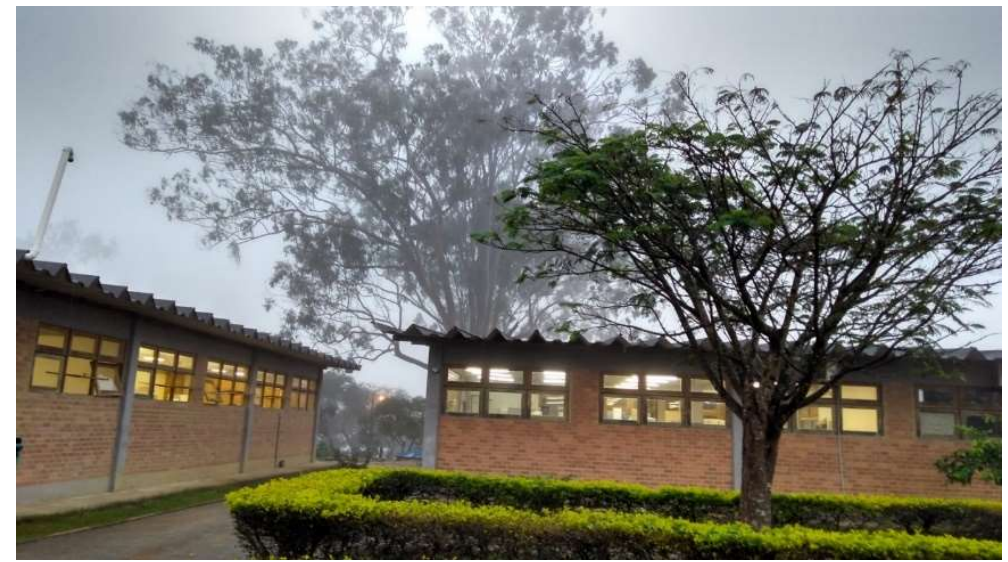

Figura 2: Condições climáticas do ambiente durante as reações de fotodegradação.

As informações de níveis de potencial energético solar coletadas pelo sistema automático se mostraram com muitas variações ao longo do tempo. Isto foi devido à quantidade de nuvens que transitaram pelo céu no momento da coleta de dados conforme mostrado na Figura 3.

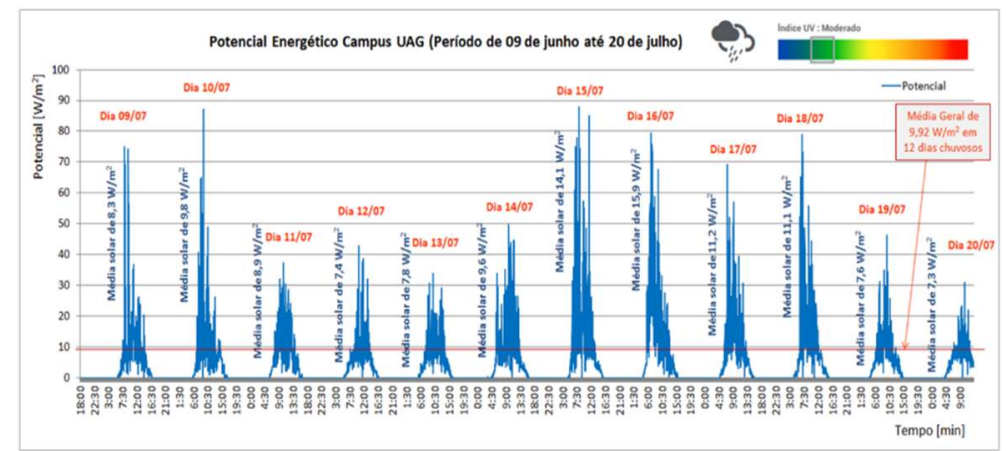

Figura 3: Dados de potencial energético medidos durantes o experimento.

A Figura 4 mostra o perfil energético medido durante o período diurno. Nota-se que a incidência solar aumenta conforme o trânsito solar seguindo um perfil de parábola (curva de tendência em vermelho). Esta informação é muito importante para se programar o melhor horário para o uso do reator fotoquímico.

Mesmo com o céu bastante encoberto, é possível obter níveis de energia solar que podem ser utilizados pelo reator fotoquímico para a degradação do contaminante. Porém a medição feita neste período de tempo nublado com condições de baixo aproveitamento energético solar é de grande importância, pois valores maiores serão obtidos em dias mais claros aumentando a eficiência do reator. A média energética total durante o monitoramento de duas semanas foi de $9,92 \mathrm{~W} / \mathrm{m} 2$. 


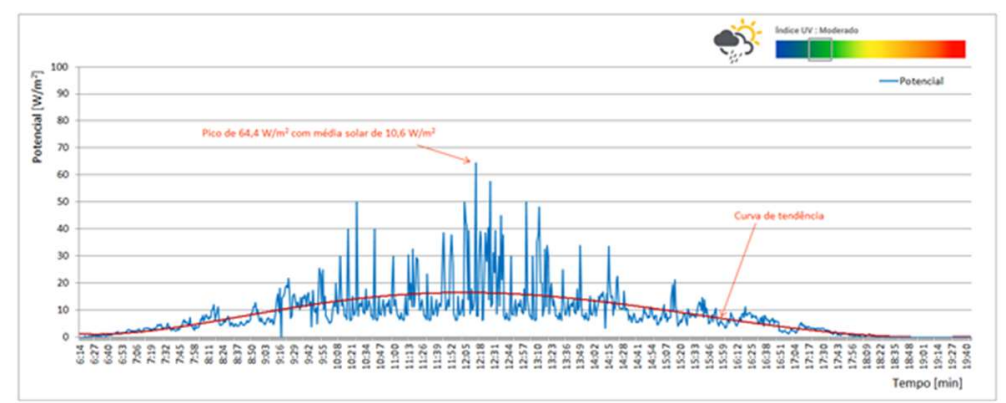

Figura 4: Dados coletados pelo processo para o perfil energético captado pelo equipamento.

Já o estudo realizado no dia do experimento de fotodegradação, foi possível verificar vários picos energéticos durante o dia conforme mostrado na Figura 5, onde se apresenta o estudo da média energética solar para um período diurno. O cálculo é baseado na área da curva medida pelos sensores. Pode-se verificar que existes picos energéticos devido as passagens de nuvens no local.

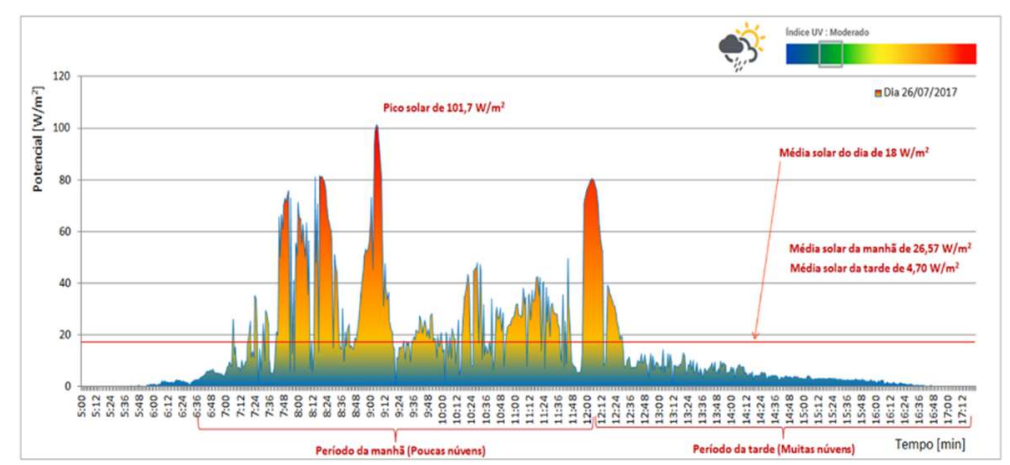

Figura 5: Dados de potencial para a média energética solar em um período diurno.

É possível verificar que, embora se tenha conseguido obter picos de $101,7 \mathrm{~W} / \mathrm{m}^{2}$ em um dia com muitas nuvens, a média do potencial energético durante um período nublado é de $10,25 \mathrm{~W} / \mathrm{m}^{2}$. Os dados coletados pelo sensor durante a corrida do experimento foi de $65,8 \mathrm{~W}$.

O experimento foi realizado seguindo o planejamento experimental descrito na Tabela 1 tanto para os dados da radiação solar apresentados na Figura 5, quanto para a lâmpada UV E27 60W. Em seguida foi realizado um ajuste dos dados obtidos para um modelo cinético por RNA. A rede neural resultante do treinamento com os dados do Azul brilhante FCF está demonstrada na Figura 6.

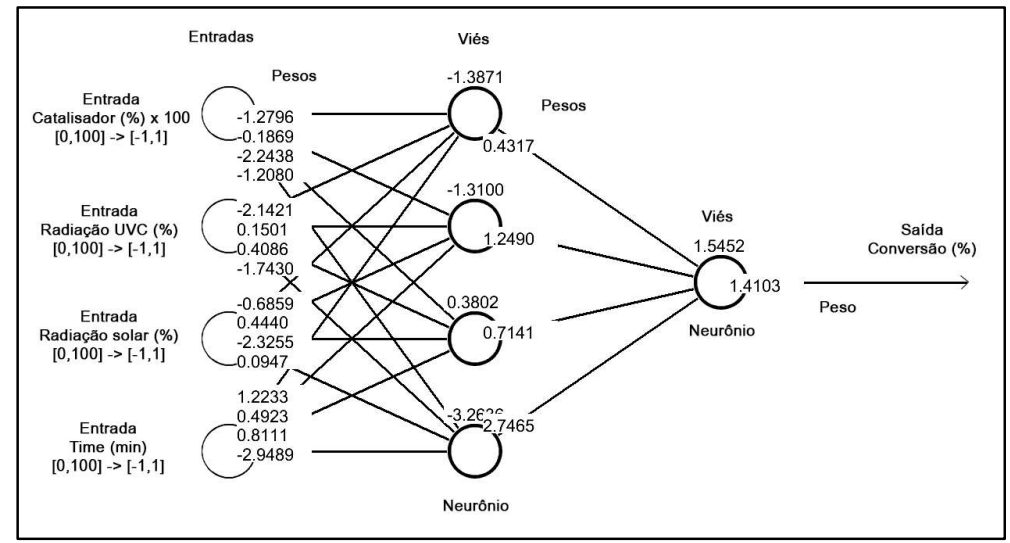

Figura 6: Rede neural resultante do treinamento para a degradação do Azul brilhante FCF.

A descrição gráfica da estrutura da rede exigiu 23813 iterações no tempo de 30 minutos para que 
houvesse a estabilização do treinamento da mesma. Para realizar o cálculo a rede multiplica os pesos (valores expostos acima das linhas de conexão) pela entrada e soma ao viés (valor acima dos neurônios) e aplicado na função sigmoid (Equação 1). O resultado é novamente multiplicado por um peso e consequentemente o resultado é passado adiante na rede neural.

Este modelo é capaz de prever a concentração do corante no intervalo 0 a 1 para as condições dadas de intensidade de radiação UV e solar (\%), quantidade de $\mathrm{ZnO}$ e tempo, respectivamente. A rede recebe valores normalizados no intervalo $[0,100] \rightarrow[-1,1]$ representando o tempo, ou porcentagem dependendo da variável. Dessa forma, a saída também é normalizada $[-1,1] \rightarrow[0.025,1]$ ficando claro que os valores de pesos e vieses resultantes do treinamento são nada mais do que parâmetros de um modelo matemático. 0 cálculo da rede treinada pode ser aplicado em qualquer linguagem de programação a partir do pseudocódigo subdividido em 3 partes: normalização da entrada, cálculo da rede e de normalização da saída. 0 pseudocódigo está descrito na Figura 7 abaixo.

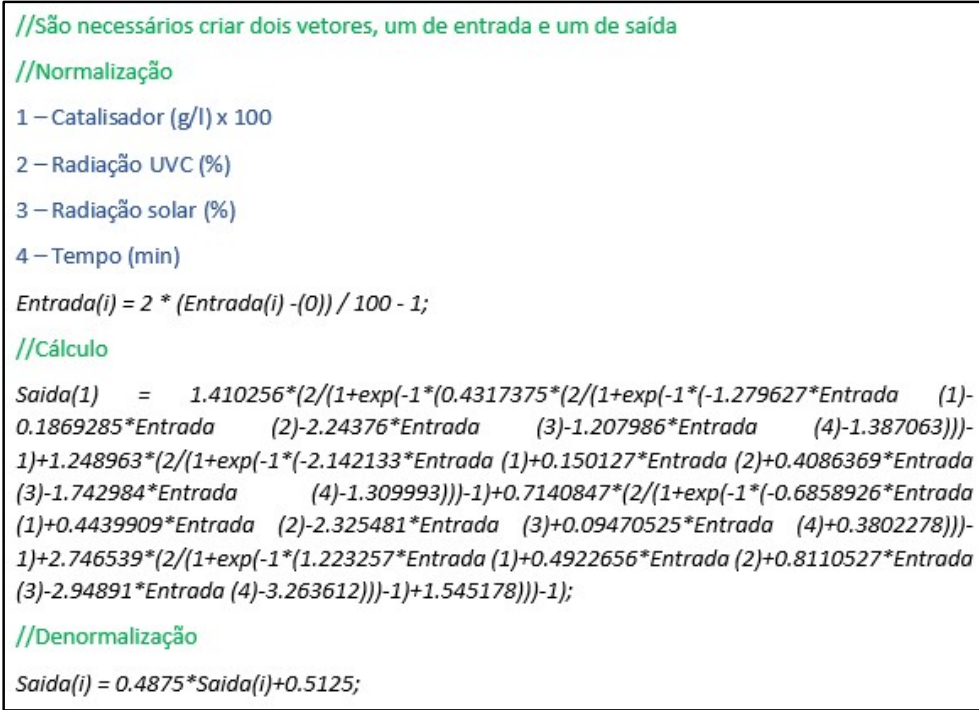

Figura 7: Pseudocódigo da rede neural já treinada com os devidos parâmetros.

A Equação 1 (acima descrita) permite a reprodução dos resultados obtidos pela geração da RNA. Para o treinamento, todos os dados experimentais gerados foram utilizados. A degradação mais rápida ocorreu utilizando a radiação solar e $0.35 \mathrm{~g} / \mathrm{l}$ de $\mathrm{ZnO}$ utilizada no reator. Os resultados do modelo e os resultados experimentais foram comparados nas Figuras 8 e 9 a seguir.

Os gráficos das Figuras 8 e 9 expõe a concordância entre os dados experimentais e os resultados da RNA para o conjunto de condições experimentais. 0 erro absoluto médio observado foi de 0,0264 , o que leva a um $R^{2}$ de 0,9674 . A única observação a se fazer é que o modelo não se ajusta adequadamente para tempos curtos durante a degradação utilizando radiação solar, porém se adequa bem para tempos longos como observados na Figura 9. Desta forma é possível constatar que as redes neurais podem descrever matematicamente o processo. Esta pode ser corroborada pela literatura reforçando a aplicação da metodologia (BARBOSA et al., 2019; NASCIMENTO JUNIOR et al., 2017; AQUINO et al., 2019; ROCHA et al., 2017; SANTANA et al., 2019). Desta forma é possível concluir que a utilização de redes neurais tem aplicação para modelar complexos sistemas de degradação. 

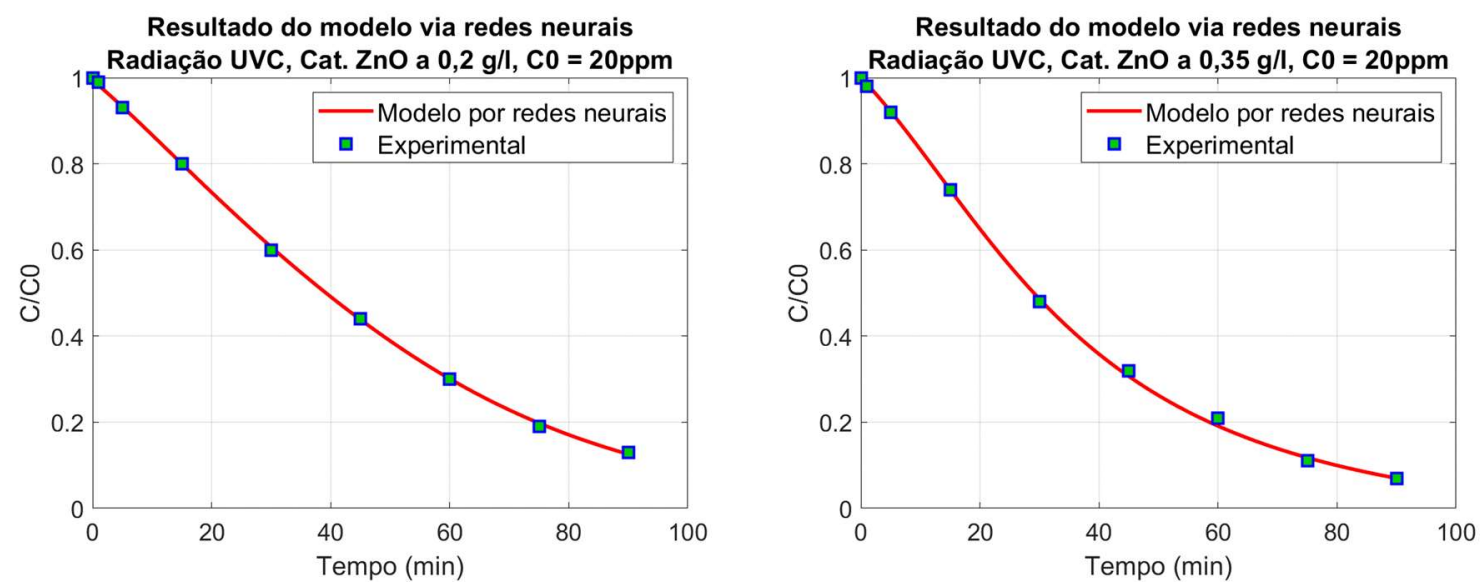

Figura 8: Gráfico comparativo entre os dados experimentais e dados provenientes do modelo neural. Perfil de ajuste para a UVC.
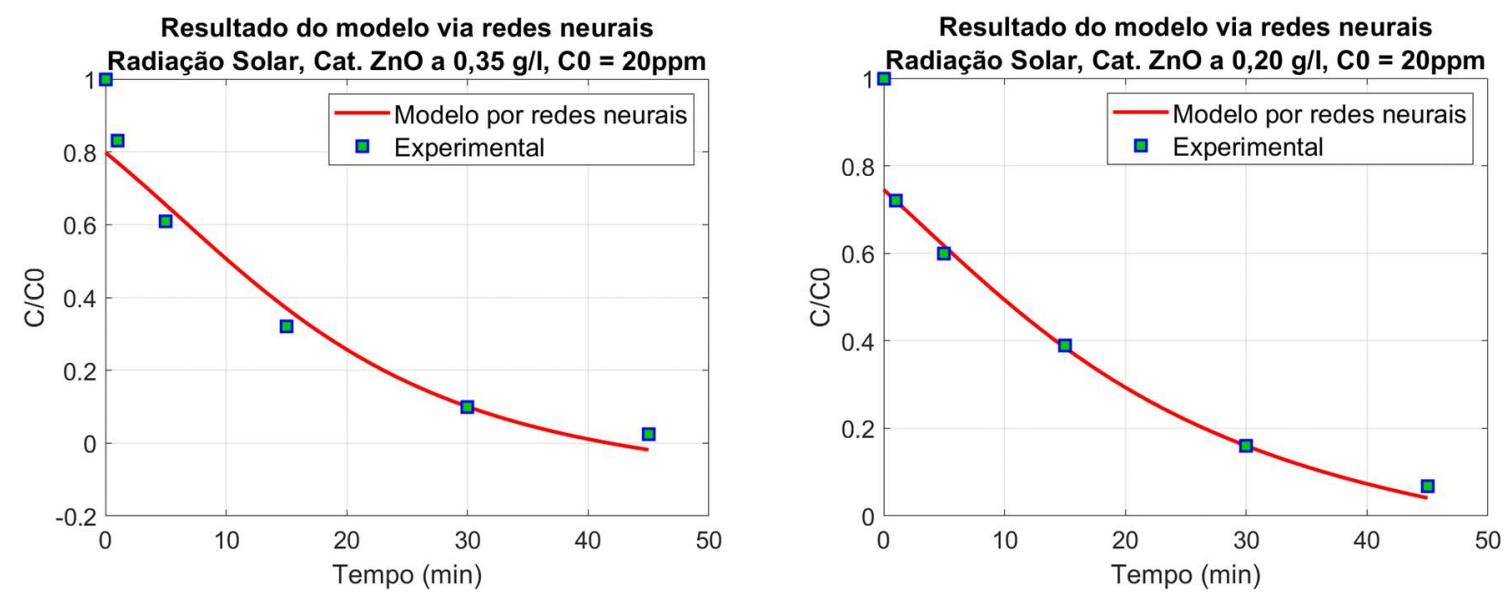

Figura 9: Gráfico comparativo entre os dados experimentais e dados provenientes do modelo neural. Perfil de ajuste para a radiação solar.

\section{CONCLUSÕES}

As medidas do potencial energético coletadas mostraram que a incidência solar aumenta conforme o trânsito solar formando um perfil parabólico. O período ideal para a realização de experimentos fotocatalíticos com fonte de energia solar ficou das 10 às 15 horas. Também foi notado uma grande oscilação do potencial energético, pois foram obtidos picos máximos de $101,7 \mathrm{~W} / \mathrm{m}^{2}$ em um dia com muitas nuvens onde a média do potencial energético foi de $10,25 \mathrm{~W} / \mathrm{m}^{2}$.

As redes neurais se mostraram capazes de se ajustar aos dados experimentais mesmo sob as diferentes fontes e quantidade de fotocatalisador, o que possibilita o desenvolvimento de um modelo robusto para descrever a degradação do Azul brilhante FCF, e com isso foi possível representar a influência de diversos fatores na degradação resultando em um erro absoluto médio de 0,0264 e um $R^{2}$ de 0,9674 para todo o conjunto de dados cinéticos.

Dessa forma conclui-se que o ajuste cinético via redes neurais pode ser explorado ao realizar experimentos de fotocatálise heterogênea na remoção de poluentes. E que mesmo diante de um clima mais ameno comparado a outras cidades do agreste pernambucano, é possível remover poluentes com eficiência mesmo sob baixo potencial energético. 


\section{REFERÊNCIAS}

AQUINO, R. V. S.; BARBOSA, A. A.; RIBEIRO, L. B.; OLIVEIRA, A. F. B.; SILVA, J. P.; AZOUBEL, P. M.; ROCHA, O. R. S.. Degradation of leaf green food dye by heterogeneous photocatalysis with $\mathrm{TiO} 2$ over a polyethylene terephthalate plate. Chemical Papers, v.1, p.1-12, 2019. DOI: http://doi.org/10.1007/s11696-019-00804-y

ASGHAR, A.; RAMAN, A. A. A.; DAUD, W. M. A. W.. Advanced oxidation processes for in-situ production of hydrogen peroxide/hydroxyl radical for textile wastewater treatment: a review. Journal of Cleaner Production, v.87, p.826-838, 2015. DOI: http://doi.org/10.1016/j.jclepro.2014.09.010

BARBOSA, A. A.; AQUINO, R. V. S.; OLIVEIRA, A. F. B.; DANTAS, R. F.; SILVA, J. P.; DUARTE, M. M. M. B.; ROCHA, O. R. S.. Development of a new photocatalytic reactor built from recyclable material for the treatment of textile industry effluents. Desalination and Water Treatment, v.151, p.8292, 2019. DOI: http://doi.org/10.5004/dwt.2019.23905

BERGSTRA, J.; BENGIO, Y.. Random search for hyperparameter optimization. Journal of Machine Learning Research, v.13, p.281-305, 2012.

CUERDA-CORREA, E. M.; ALEXANDRE-FRANCO, M. F.; FERNÁNDEZ-GONZÁLEZ, C.. Advanced Oxidation Processes for the Removal of Antibiotics from Water: An Overview. Water, v.12, n.102, 2020. DOI: http://doi.org/10.3390/w12010102

COPETE-PERTUZ, L.; PÉREZ-GRISALES, M. S.; CASTRILLÓNTOBÓN, M.; LONDOÑO, G. A. C.; GARCÍA, G. T.; MARTÍNEZ, A. L. M.. Decolorization of Reactive Black 5 Dye by Heterogeneous Photocatalysis with TiO2/UV. Rev. Colomb. Quim., v.47, n.2, p.36-44,

2018. DOI: https://doi.org/10.15446/rev.colomb.quim.v47n $\underline{2.67922}$

DENG, Y.; ZHAO, R.. Advanced Oxidation Processes (AOPs) in Wastewater Treatment. Curr Pollution Rep., v.1, p.167-176, 2015. DOI: http://doi.org/10.1007/s40726-015-0015-z

GUPTA, V. K.; KHAMPARIA, S.; TYAGI, I.; MALVIYA, A.. Decolorization of mixture of dyes: A critical review. Global J. Environ. Sci. Manage., v.1, n.1, p.71-94, 2015. DOI: http://doi.org/10.7508/giesm.2015.01.007
HAIKIN, S.. Neural networks: a comprehensive foundation. 2 ed. Upper Saddle River: Prentice Hall, 1999.

KNIJNIK, R.. Energia e meio ambiente em Porto Alegre: bases para o desenvolvimento. Porto Alegre: CPEA, 1994.

LELLIS, B.; FÁVARO-POLONIO, C. Z.; PAMPHILE, J. A.; POLONIO, J. C.. Effects of textile dyes on health and the environment and bioremediation potential of living organisms. Biotechnology Research and Innovation, 2019. DOI: http://doi.org/10.1016/i.biori.2019.09.001

MELO, M. M. M.; ROCHA, E. M. R.; SILVA, E. L.. Solar heterogeneous photocatalysis (ZnO/UV) for textile dyes removal. Environmental Quality Management, v.28, n.1, p.65-71, 2018. DOI: http://doi.org/10.1002/tqem.21584

MISTURA, C. M.; SCHNEIDER, I. A. H.; VIEIRA, Y.. Heterogeneous Photocatalytic Degradation of Dyes in Water/Alcohol Solution Used by the Brazilian Agate Industry. Geomaterials, v.9, p.29-39, 2019. DOI: https://doi.org/10.4236/gm.2019.91003

NASCIMENTO JUNIOR, W. J.; ROCHA, O. R. S.; DANTAS, R. F.; BARBOSA, A. A.; SILVA, J. P.. Kinetic study of food dyes removal from aqueous solutions by solar heterogeneous photocatalysis with artificial neural networks and phytotoxicity assessment. Desalination and Water Treatment, v.104, p.304-314, 2017. DOI: http://doi.org/10.5004/dwt.2018.21841

ROCHA, O. R. S.; DANTAS, R. F.; NASCIMENTO JUNIOR, W. J.; FUJIWARA, Y.; DUARTE, M. M. M. B.; SILVA, J. P.. Kinetic study and modelling of cephalexin removal from aqueous solution by advanced oxidation processes through artificial neural networks. Desalination and Water Treatment, v.92, p.72-79, 2017. DOI: http://doi.org/10.5004/dwt.2017.21438

SANTANA, I. L. S.; BARBOSA, A. A.; SILVA, M. G.; AQUINO, R. V. S.; NEVES, N. S. C. S.; SILVA, J. P.; FERREIRA, I. H. R.; ROCHA, O. R. S.. Titanium dioxide immobilization in recycled aluminum net for degradation of textile dye by Heterogeneous Photocatalysis through neural networks. Revista Eletrônica em Gestão, Educação e Tecnologia Ambiental, v.23, p.1-12, 2019. DOI: http://doi.org/10.5902/2236117037718

A CBPC - Companhia Brasileira de Produção Científica (CNPJ: 11.221.422/0001-03) detém os direitos materiais desta publicação. Os direitos referem-se à publicação do trabalho em qualquer parte do mundo, incluindo os direitos às renovações, expansões e disseminações da contribuição, bem como outros direitos subsidiários. Todos os trabalhos publicados eletronicamente poderão posteriormente ser publicados em coletâneas impressas sob coordenação da Sustenere Publishing, da Companhia Brasileira de Produção Científica e seus parceiros autorizados. Os (as) autores (as) preservam os direitos autorais, mas não têm permissão para a publicação da contribuição em outro meio, impresso ou digital, em português ou em tradução. 